RESIDENT

\& FELLOW

SECTION

Section Editor

Mitchell S.V. Elkind,

MD, MS

Lama M. Chahine, MD

Michel J. Berg, MD

Address correspondence and reprint requests to Dr. Lama Chahine, S100-C, 9500 Euclid Avenue, Cleveland Clinic, Cleveland, $\mathrm{OH} 44195$

chahinl@ccf.org

\title{
Clinical Reasoning: Cerebral cavernous malformations
}

\section{SECTION 1}

A 40-year-old man presented for management of seizures. His first seizure was 5 years earlier. Evaluation at that time revealed a hemorrhagic lesion near the occipital horn of the left lateral ventricle. Incomplete surgical excision was performed with indeterminate pathology suggestive of an astrocytoma. MRI demonstrated 7 separate lesions consistent with cavernous malformations. One measured $1.5 \mathrm{~cm}$ in diameter with T2 heterogeneous signal surrounded by a rim of low signal in the medial left temporal lobe. His current seizures have a complex partial semiology and occur 2-4 times per month despite treatment with 2 antiepileptic drugs (AEDs).

\section{Questions for consideration:}

1. Discuss the relationship of cavernous malformations to epilepsy.

2. Discuss the pathologic characteristics, differential diagnosis, and diagnostic evaluation of cavernous malformations.

GO TO SECTION 2 
SECTION 2

Epileptic seizures are the most common clinical presentation of supratentorial cerebral cavernous malformations (CCMs). ${ }^{1}$ Since functional neural tissue is not present within CCMs, these lesions are not intrinsically epileptogenic. Rather, they cause seizures through effects on adjacent brain tissue. CCMs have a propensity for recurrent microhemorrhage into adjacent brain resulting in surrounding hemosiderin staining and gliosis. ${ }^{1}$ These effects, and perhaps local venous hypertension, ischemia, and inflammation, predispose to epileptogenicity.

Grossly, CCMs appear raspberry-like, being discretely lobulated, well-circumscribed, and red to purple. Microscopically, CCMs consist of enlarged sinusoidal channels, or caverns, with a simple endothelial lining devoid of elastin and smooth muscle. There is a fibrous adventitia of variable thickness. The caverns may be filled with blood or thrombus. There is no intervening brain parenchyma except possibly at the periphery of the CCM. Hemosiderin is often deposited in the parenchyma sounding the CCM. ${ }^{1}$

CCMs are low flow lesions that are typically not seen on angiography. MRI is the most sensitive and specific imaging modality for detecting CCMs. CCMs have a characteristic appearance on MRI: they are well-defined, ovoid lesions with a central core of mixed signal on T1-weighted and T2-weighted images and a peripheral rim of hypointensity (figure). However, these findings are not pathognomonic for CCMs.

Several types of hemorrhagic neoplasms, including primary brain tumors and metastatic tumors, may be confused with vascular malformations, including CCMs. ${ }^{1}$ CCMs may be distinguished from hemorrhagic tumors in that mass effect out of proportion to the hemorrhage and edema persisting weeks to months is more typical of tumors. On MRI, CCMs may be misdiagnosed as other forms of vascular malformations, particularly in the presence of resolving hemorrhage. When angiography is unrevealing, a vascular malformation seen on MRI may be misdiagnosed as a thrombosed arteriovenous malformation (AVM). ${ }^{2}$ The presence of subarachnoid or intraventricular hemorrhage or feeding or draining vessels adjacent to the lesion suggests an AVM. Capillary malformations do not commonly cause neurologic symptoms or bleed, yet they may rarely appear similar to CCMs. The absence of intervening brain parenchyma among the caverns of a CCM is a feature useful in distinguishing CCMs from other vascular malformations pathologically. ${ }^{1}$
Figure

Typical appearance of a cerebral cavernous malformation, with a central core of mixed signal and a peripheral rim of hypointensity on (A) T1-weighted and (B) T2-weighted, (C) fluid-attenuated inversion recovery, and (D) gradient-echo sequences
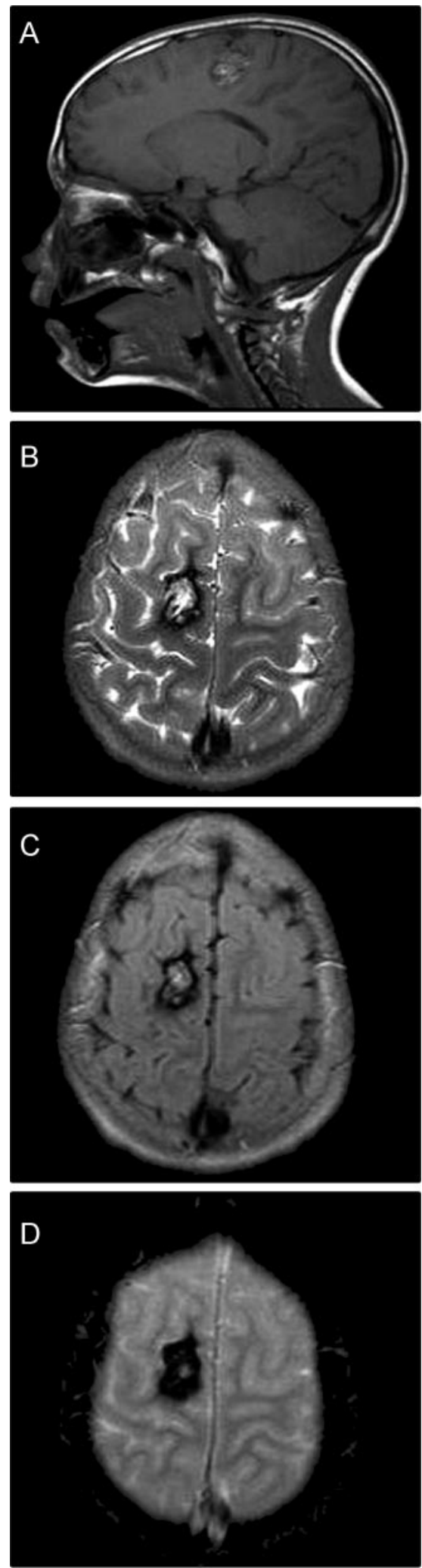
The patient is admitted for video-EEG monitoring, which reveals left temporal lobe seizure onset.

\section{Questions for consideration:}

1. Discuss the epilepsy surgery options.
2. Is directed beam radiosurgery an option?

3. What factors would influence your decision to recommend medical management, surgery, or radiosurgery? 


\section{SECTION 3}

The presence of a primary epileptogenic lesion may induce epileptogenic foci distant from the lesion, especially within the mesial temporal lobe structures. With time, the remote focus may become independently epileptogenic. The more frequent the seizures, the more likely that a secondary focus will become permanent. Thus, when medical therapy has failed to control seizures, early surgical evaluation is indicated. ${ }^{1}$ Assuming appropriate medication treatment is confirmed, if he continues to have several seizures per month while on appropriate AEDs, he meets criteria for medically intractable epilepsy.

Patients with multiple CCMs and epilepsy should be considered for surgery if electroclinical findings correlate with a single lesion. These patients may be able to be managed similarly to patients with a single CCM. ${ }^{1}$

The epilepsy surgery options available for temporal lobe epilepsy due to a CCM include lesionectomy or lesionectomy with hippocampal/mesial temporal lobe resection. In cases of extratemporal CCMs, cortisectomy, or removal of the cortex surrounding the CCM, can be considered in addition to lesionectomy. When a developmental venous anomaly (DVA) is associated with a CCM (approximately $25 \%$ of patients), during surgery the DVA should be spared to avoid venous engorgement with subsequent venous infarction. ${ }^{1}$

While radiosurgery for treatment of angiographically evident AVMs is well established, its use for CCMs is controversial. Radiosurgery may entail a greater risk of radiation-related complications for CCMs. In addition, unlike AVMs, obliteration of CCMs following radiosurgery cannot be documented angiographically or with any other current imaging modality.

Incidentally discovered CCMs are probably best followed conservatively in the majority of cases. ${ }^{1}$ The major role of medical management in CCMs is the control of epilepsy. Surgery is generally recom- mended for patients with CCMs with intractable seizures, previous hemorrhage, and progressive neurologic deficit. Neurologically intact patients with brainstem CCMs that do not have contact with the pial surface may be managed conservatively. Surgery may be indicated when there is progressive neurologic deterioration, with or without recurrent hemorrhage, if the lesion lies near the pial surface, or if a non-eloquent tissue corridor provides access to the lesion.

For young patients with asymptomatic CCMs that are enlarging, presumably due to repeated asymptomatic hemorrhages, excision may be considered if they are solitary and easily accessible. ${ }^{4}$ Radiosurgery may be considered for patients in whom microsurgical resection carries high risk.

There is limited experience with radiosurgery in patients with CCM. Of particular concern is evidence that CNS radiation may increase the occurrence of CCMs. There are reports of children developing CCMs following CNS radiation for leukemia. ${ }^{5}$ A "two-hit" genetic mechanism may provide an explanation of this phenomenon. In familial CCM, germline mutations occur in one of the 3 genes so far associated with CCMs. A second "hit" (somatic mutation) is postulated to occur in the other allele leading to loss of function of the CCM gene, causing a CCM to form.

Five years later, this patient's epilepsy is controlled. He contacts you urgently because of the abrupt onset of dizziness and dense hemisensory loss over his left body (arm, trunk, leg). A CT scan reveals a $0.4-\mathrm{cm}$ hemorrhage in his pontine tegmentum.

\section{Questions for consideration:}

1. What is the natural history of a cavernous malformation?

2. How often should MRIs be performed in a patient with cavernous malformations but no acute symptoms? What acquisition sequences should be obtained? 


\section{SECTION 4}

Symptoms commonly resulting from CCMs include seizures, focal neurologic deficits, hemorrhage, and headache. ${ }^{1}$ Up to $50 \%$ of patients who are initially asymptomatic at the time of diagnosis later develop symptoms referable to the CCM. ${ }^{3}$

In one study, patients diagnosed with CCMs after evaluation for neurologic symptoms had a hemorrhage rate of $3.1 \%$ per patient-year. ${ }^{4}$ In another prospective study, the rate was $0.6 \%$ for patients presenting with incidental CCM or seizures and $4.5 \%$ in patients presenting with hemorrhage. ${ }^{6}$

Serial MRI has documented the appearance of new lesions in patients with sporadic and familial CCM. These lesions are thought to have formed de novo though some authors have suggested they are lesions that were previously present but too small to be seen on prior MRI.?

While there are no official guidelines, gradient echo sequences every 1-2 years may be used to follow asymptomatic patients with $\mathrm{CCMs}^{8}$ and to monitor for lesion growth. If the lesions show stability over time (2-3 scans), the interval of imaging may be increased to every 3-5 years unless new symptoms develop.

This patient should be admitted to an intensive care unit for close monitoring. If the patient's neurologic condition deteriorates, surgery may be indicated. ${ }^{1}$ The optimal timing of surgery for brainstem CCMs after hemorrhage is controversial, however. In the absence of indications necessitating emergent surgery, time should be allowed for clinical stabilization. Surgery in the subacute phase has been advocated as there is evidence for worse outcome if surgery is delayed beyond 19 days following brainstem CCM hemorrhage. ${ }^{9}$

Two years later, the patient's 14-year-old son develops a severe headache and presents for evaluation. An MRI reveals several small cerebral cavernous malformations.

\section{Questions for consideration:}

1. Discuss the familial (vs sporadic) nature of cavernous malformations.

2. Are there any lifelong medical management recommendations that should be given to the son and your patient?

GO TO SECTION 5 


\section{SECTION 5}

Familial CCM was originally described in a Mexican American family ${ }^{10}$ but has now been demonstrated in other ethnicities. Patients with familial CCMs are significantly more likely to harbor multiple CCMs; more than $70 \%$ of patients with the familial form will have multiple CCMs. ${ }^{10}$ In patients with familial CCMs, individual CCMs are not more likely to hemorrhage, but the hemorrhage rate per patient per year is higher given the presence of multiple CCMs.

Familial CCM is autosomal dominant. Clinical penetrance is incomplete in many families described; MRI penetrance is higher. Penetrance increases with age. ${ }^{8}$ Familial CCM is attributed to mutations at 3 different loci: CCM1 on chromosome 7q21, CCM2 on chromosome $7 \mathrm{p} 15$, and CCM3 on chromosome 3q25. CCM1 has been identified as the KRIT-1 gene. Its product is a microtubule-associated protein involved in endothelial cell-cell and cell-extracellular matrix interactions. A founder CCM1 mutation is present in most familial CCM patients of Hispanic American descent and other CCM1 mutations are present in $40 \%$ of Caucasian patients with familial CCMs. The CCM2 gene has been identified as MGC4607 (malcavernin), which encodes a phosphotyrosine-binding domain, and may be involved in integrin signaling. CCM2 mutations account for another $40 \%$ of familial CCMs. The programmed cell death gene 10 (PCDC10) has been identified as the CCM3 gene; it may play a role in apoptosis. Apoptosis in smooth muscle cells has been shown to be mediated by the $\beta 1$ integrin signaling cascade, which KRIT-1 interacts with via the phosphotyrosine-binding domain of MGC4607. These data suggest that these 3 genes may function in the same cellular pathway, and that disruption of this pathway leads to CCM formation. ${ }^{8}$ Genetic testing is commercially available for all 3 CCM genes.

There is controversy regarding the need to restrict certain activities. Avoidance of activities in which there is a high risk of head trauma such as contact sports is encouraged. Other lifestyle modifications, such as not driving, will depend on the patient's clinical manifestations, such as seizures. Antiplatelet agents and anticoagulants should be avoided in patients with CCMs, if possible. Medications that lower seizure threshold should be avoided. Good sleep hygiene and minimization of emotional and physical stress are important in the management of patients with epilepsy. People who have CCMs should be educated regarding signs and symptoms of seizures and hemorrhage that should prompt medical attention.

\section{ACKNOWLEDGMENT}

Modified from the 2007 winning essay of the Angioma Alliance US Neurology Resident Essay Contest awarded to Dr. Chahine.

\section{DISCLOSURE}

Dr. Chahine reports no disclosures. Dr. Berg has served as a consultant for Medscape (grant support from Abbott) and Harris Interactive (grant support from GlaxoSmithKline) and serves on the scientific advisory board of the Angioma Alliance.

\section{REFERENCES}

1. Awad IM, Robinson JR. Cavernous Malformations. Park Ridge, IL: American Association of Neurological Surgeons; 1993.

2. Robinson JR Jr, Awad IA, Masaryk TJ, Estes ML. Pathological heterogeneity of angiographically occult vascular malformations of the brain. Neurosurgery 1993;33:547554; discussion 554-555.

3. Robinson JR Jr, Awad IA, Magdinec M, Paranandi L. Factors predisposing to clinical disability in patients with cavernous malformations of the brain. Neurosurgery 1993;32: 730-735; discussion 735-736.

4. Moriarity JL, Clatterbuck RE, Rigamonti D. The natural history of cavernous malformations. Neurosurg Clin N Am 1999;10:411-417.

5. Larson JJ, Ball WS, Bove KE, Crone KR, Tew JM. Formation of intracerebral cavernous malformations after radiation treatment for central nervous system neoplasia in children. J Neurosurg 1998;88:51-56.

6. Kondziolka D, Lunsford LD, Kestle JR. The natural history of cerebral cavernous malformations. J Neurosurg 1995;83:820-824.

7. Zabramski JM, Wascher TM, Spetzler RF, et al. The natural history of familial cavernous malformations: results of an ongoing study. J Neurosurg 1994;80:422-432.

8. Labauge P, Denier C, Bergametti F, Tournier-Lasserve E. Genetics of cavernous angiomas. Lancet Neurol 2007;6: 237-244

9. Bruneau M, Bijlenga P, Reverdin A, et al. Early surgery for brainstem cavernomas. Acta Neurochir 2006;148:405414.

10. Rigamonti D, Hadley MN, Drayer BP, et al. Cerebral cavernous malformations: incidence and familial occurrence. N Engl J Med 1988;319:343-347. 


\title{
Neurology
}

\author{
Clinical Reasoning: Cerebral cavernous malformations \\ Lama M. Chahine and Michel J. Berg \\ Neurology 2009;73;e44-e49 \\ DOI 10.1212/WNL.0b013e3181b59a5b
}

This information is current as of August 31, 2009

\section{Updated Information \& Services}

References

Subspecialty Collections

Permissions \& Licensing

Reprints including high resolution figures, can be found at: http://n.neurology.org/content/73/9/e44.full

This article cites 9 articles, 0 of which you can access for free at: http://n.neurology.org/content/73/9/e44.full\#ref-list-1

This article, along with others on similar topics, appears in the following collection(s):

All Epilepsy/Seizures

http://n.neurology.org/cgi/collection/all_epilepsy_seizures

Intracerebral hemorrhage

http://n.neurology.org/cgi/collection/intracerebral_hemorrhage Other cerebrovascular disease/ Stroke

http://n.neurology.org/cgi/collection/other_cerebrovascular_disease_st roke

Information about reproducing this article in parts (figures,tables) or in its entirety can be found online at:

http://www.neurology.org/about/about_the_journal\#permissions

Information about ordering reprints can be found online:

http://n.neurology.org/subscribers/advertise

Neurology ${ }^{\circledR}$ is the official journal of the American Academy of Neurology. Published continuously since 1951, it is now a weekly with 48 issues per year. Copyright. All rights reserved. Print ISSN: 0028-3878. Online ISSN: 1526-632X.

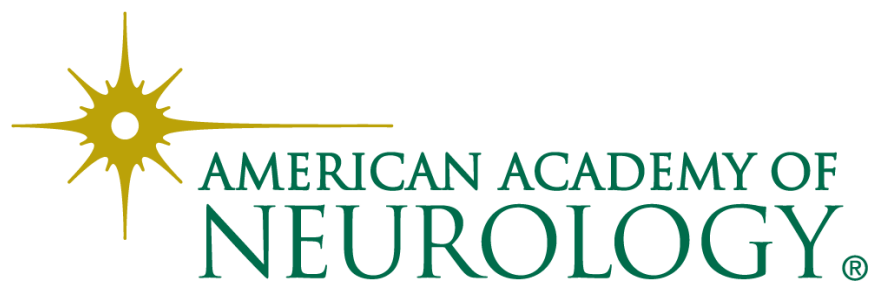

